\title{
DERECHOS DE LOS PUEBLOS INDÍGENAS, EXTRACTIVISMO Y LUCHA DEL PUEBLO YAQUI
}

\author{
INDIGENA LLAQTAKUNAPA KAMACHIYNINKUNA, \\ HURQUYMANTA HINALLATAQ YAQUI AYLLU \\ SAYAPAKUSQANMANTA
}

\section{INDIGENOUS PEOPLES RIGHTS, EXTRACTIVISM AND YAQUI PEOPLE STRUGGLE}

\section{Enrique F. Pasillas Pineda ${ }^{(1)}$}

Ch'uyanchakuy: Kay qillqaypa munayninqa llaqtanchikkunapa pachamamanchik amachaspa maqanakusqanmanta chaqway mastariymi, Derecho fundamental nisqa amaña imaymana kawsayninchikta suwanankupaq, chaytaqa qawarisun Yaqui ayllu puriyninmanta. Chaqwaymanta lluqsisqanqa, yuyaychakusqa propuesta nisqaqa, riqsichinmi imaynas Mexico hatun Ilaqtapi, chay Tribu Yaqui, Constitución Internacional uyanpi, Estado ukupi saruchasqallapuni tarikusqanmanta, munasqallan wistu wistulla imapis purisqanta chiqanchana kanqa maypachachus qipa punchawkunaman Estado social nisqamanta, derecho nisqamantapas rimayta munaspaqa, chayraqchá huntakunqa chay norma fundamental nisqapas, chay obligaciones internacionales nisqapis chay derechos indígenas matipaq, chaninchaq.

Yuyaysapa simikuna: Derechos Indigenas, Pachamama wañuchiy, Yaqui ayllu.

Resumen: El objetivo del presente papel de trabajo es proponer una discusión sobre la lucha indígena por la defensa contra el despojo de los recursos naturales como un Derecho Fundamental en contra del extractivismo a través del caso de la tribu Yaqui. El resultado de la discusión y análisis propuestos, refleja que a pesar del marco constitucional internacional vigente en México, la tribu Yaqui ha sido víctima de notorios abusos por parte de diversas instituciones públicas

(1) Enrique F. Pasillas Pineda. Licenciado en Derecho. Máster oficial en Estudios Jurídicos Avanzados y Medio Ambiente (UNIA). Doctorando en Ciencias Jurídicas. Facultad de Derecho. Universidad de Granada (UGr), España. Correo electrónico: efpasillas@correo.ugr.es 
del Estado; abusos y desviaciones de poder que deben ser corregidos si es que quiere hablar en el futuro de un estado social y de derecho que cumple con la norma fundamental y también con sus obligaciones internacionales en materia de derechos indígenas.

Abstract: The objective of this working paper is to propose a discussion on the indigenous struggle for the defense of natural resources as a fundamental right against extractivism and the dispossession of natural resources through the case of the Yaqui tribe. The result of the proposed discussion and analysis, reflects that despite the current international constitutional framework in Mexico, the Yaqui tribe has been the victim of notorious abuses by various public institutions of the State; abuses and deviations of power that must be corrected if we want to talk on the future about a rightful social and legal state that complies with the fundamental norm and also with its international obligations on the indigenous people's rights.

Palabras clave: Derechos Indígenas, Extractivismo, Yaquis 


\section{Introducción}

Los pueblos indígenas seencuentran entrelas poblaciones más vulnerables, desfavorecidas y marginadas del mundo. Las Naciones Unidas estiman que suman más de 370 millones de personas que viven en unos 90 países. Constituyen aproximadamente el 5 por ciento de la población mundial y constituyen el 15 por ciento de los pobres del mundo y un tercio de los extremadamente pobres. ${ }^{(2)}$ Por su parte, el estado-nación mexicano cuenta entre sus habitantes en 2018 a unos 16 millones de personas auto- adscritas como indígenas, distribuidas entre 65 etnias, que hablan hasta 68 lenguas originarias con 364 variantes lingüísticas, (casi el 8\% de la población nacional habla alguna lengua indígena) lo que pone a México entre los diez países con mayor diversidad lingüística del mundo. ${ }^{(3)}$ De manera que los pueblos originarios conforman una presencia milenaria en el territorio del actual de México, donde predomina una sociedad mestiza con componentes tanto autóctonos como migratorios de distintas épocas, pero en el que las etnias originarias ocupan casi invariablemente los escalones más bajos en el desarrollo social. ${ }^{(4)}$

Así es como entre los más de 65 pueblos indígenas mexicanos, el caso de la tribu Yaqui es paradigmático porque reviste una significación especial por varias razones. Sin duda entre las más importantes se puede señalar su férrea voluntad, demostrada muy temprano en la historia de Nueva España y luego del México independiente, por preservar su identidad, su cultura, sus territorios ancestrales y su autonomía. Aún por medio de la fuerza, cosa que se encargaron de dejar muy clara desde sus primeros contactos, todos hostiles, con las expediciones españolas que poco a poco y desde el sur, iban incursionando, ocupando y colonizando sus territorios ancestrales. ${ }^{(5)}$

(2)

BURGER, Julian. (2014). "La protección de los pueblos Indígenas en el sistema Internacional”. En: BELTRAO, J. Felipe [et al.] (coord.). Derechos Humanos de los Grupos Vulnerables. Manual. Barcelona, Red de Derechos Humanos y Educación Superior, 2014. Recuperado en: https:/e-archivo.uc3m.es/ handle/10016/19792

(3) Secretaría de Cultura, Gobierno Federal: www.gob.mx/cultura, http://www.gob.mx/cultura/ articulos/la-constitucion-mexicana-en-tu-lengua?idiom=es

(4) "La precariedad en las condiciones de vida de la población indígena en México ha sido sistemáticamente mayor a la de la población no indígena. Aun en la actualidad, las personas que pertenecen a los pueblos originarios concentran diversos rasgos de desventaja social que las mantienen en una situación de rezago respecto al resto de la población. Muestra de ello es que, de acuerdo con las estimaciones de pobreza elaboradas por el CONEVAL, el porcentaje de población hablante de lengua indígena (HLI) que se encontraba en pobreza en 2012 casi duplicaba al de la población no hablante (76.8 frente a 43.0 por ciento) y el de población en pobreza extrema fue casi cinco veces mayor (38.0 frente a 7.9 por ciento)". CONSEJO NACIONAL DE EVALUACIÓN DE LA POLÍTICA SOCIAL (CONEVAL). La Pobreza en la población Indígena de México 2012. Pág. 12. Recuperado en: https://www.coneval.org.mx/Informes/ Coordinacion/INFORMES_Y_PUBLICACIONES_PDF/POBREZA_POBLACION_INDIGENA_2012.pdf

(5) De ello daba cuenta en 1645, el jesuita Andrés Pérez de Ribas, quien se contaba entre los primeros europeos asentados en la región yaqui, autor del célebre libro titulado: Historia de los triunfos de nuestra santa fe entre las gentes más bárbaras y fieras del nuevo orbe: conseguidos por los soldados de la milicia de la Compañía de Jesús en las misiones de la Nueva España. 
De esos primeros encuentros y desencuentros deriva una historia de conflicto constante y violento por el control del territorio y sus recursos naturales, que es denominador común en todos los conflictos socio-ambientales, modernos, si seguimos a Martínez Alier o a Víctor Toledo, especialmente a raíz del fenómeno social en Iberoamérica caracterizado como "emergencia indígena" (BENGOA, José. 2002).

Otro aspecto relevante del caso Yaqui es que a pesar de que el conflicto violento ha caracterizado sus relaciones con las sucesivas olas de invasiones extranjeras a sus territorios, los yaquis han preservado hasta nuestros días, aun expuestos constantemente a la influencia exógena, una cohesión tribal que se sustenta en la identificación con sus territorios ancestrales, donde han preservado su cultura tradicional, en lugar destacado su lengua. Lo que no es poco, pues no sobra decir que en 2018 no ocurre lo mismo con todos o siquiera con la mayoría de los pueblos y lenguas indígenas, que en muchos casos están al borde de la extinción en su propio entorno territorial ${ }^{(6)}$, especialmente en el noroeste de México.

Así, desde tiempos coloniales, los Yaquis se dieron una organización y un gobierno que fue una imbricación y mezcla entre las enseñanzas de los misioneros, la cultura del colono español de frontera: "vecinos", los llama Jiménez ${ }^{(7)}$, y sus propios usos y costumbres ancestrales, alimentados por décadas de contacto y aprendizaje, no siempre pacífico, con todo tipo de invasores extranjeros: el otro, el "salvaje" o "feroz" hombre blanco y/o mestizo ("Yori" para los yaquis).

El caso Yaqui también es relevante porque históricamente, la tribu jamás ha dudado en defender por cualquier medio a su alcance lo que entienden que son sus derechos. Como si hubieran conocido instintivamente y desde siempre aquella frase atribuida a Dworkin de que "los derechos son triunfos frente a la mayoría". Primero por las armas, enfrentándose y aun venciendo en repetidas ocasiones a fuerzas muy superiores en número y en tecnología bélica y aprovechando al límite sus conocimientos y adaptación a un entorno natural complejo.

Actualmente, en pleno siglo XXI, tampoco han dudado en asumir la lucha social pacífica, centrada en la resistencia civil, o en llevar sus reivindicaciones ante todo tipo de autoridades y tribunales, así como en enfrentarse al poder político y económico haciendo uso de las herramientas modernas de lucha que ya no pasan

(6) En la misma región noroeste de México los pueblos Guarijíos Pimas, Ópatas y Seris en Sonora, Cucapah, Paipai, Kumiai o Kiliwa en Baja California, todos son solo ejemplos regionales de un asunto que es nacional. De acuerdo con información del Instituto Nacional de Lenguas Indígenas, 27\% de las lenguas y variantes de los pueblos indios de México son habladas por menos de mil personas, lo que las pone en inminente riesgo de desaparecer. "En riesgo de desaparecer, $27 \%$ de las lenguas indígenas del país", La Jornada, 27 de agosto de 2008.

(7) JIMENEZ, Alfredo. (2006). "Los Vecinos españoles ante los indios de Frontera: el Gran Norte de Nueva España", Brocar, Cuadernos de Investigación Histórica, No.30. Recuperado en https://dialnet. unirioja.es/servlet/articulo?codigo $=2878408$ 
por la violencia, sino por el uso de herramientas modernas de comunicación social y política. Así, su resistencia civil pacífica ha incluido lo mismo manifestaciones, que marchas, caravanas, bloqueo de carreteras y autopistas, su afiliación y participación activa en el Consejo de Gobierno del Congreso Nacional Indígena de origen zapatista, así como múltiples solicitudes de acompañamiento a ONG locales, nacionales e internacionales; del mismo modo que quejas y comparecencias ante organismos internacionales, así como el uso intensivo de medios alternativos de comunicación y redes sociales.

Tampoco han dudado los yaquis en acudir a la jurisdicción especial agraria o aun a la Suprema Corte de Justicia de la Nación. Su lucha, ya bien entrado el siglo XXI, ha sido por lo general pacífica y han tenido un notorio éxito evidenciando el racismo, la corrupción y el autoritarismo del que han sido víctimas históricas, además del despojo actual de los recursos naturales de su entorno. La lucha legal y pacífica le ha generado a los Yaquis enemigos poderosos e incluso persecución penal a sus liderazgos, especialmente entre las muchas autoridades corruptas que han sido expuestas y denunciadas. Por eso, entre otras razones, la lucha yaqui constituye un paradigma de apropiación y uso pacífico y contra-hegemónico del derecho y de movilización y lucha social, cuyo ejemplo e importancia van mucho más allá del ámbito étnico o indígena, incluso mexicano o Iberoamericano, porque enarbola valores fundamentales para cualquier sociedad en cualquier tiempo.

\section{Derechos Fundamentales y libre determinación de los pueblos indígenas}

Por una parte, sabemos que la Constitución Política de los Estados Unidos Mexicanos (CPEUM, 5 de febrero de 1917), eleva al rango de Derechos Fundamentales en el orden interno a los Derechos Humanos reconocidos en los Tratados Internacionales desde la reforma de 2011 en su artículo $1^{\circ}$. Además, estatuye en su artículo $2^{\circ}$ la "plurinacionalidad" de la nación mexicana, basada esencialmente en sus pueblos originarios. Por si eso fuese poco, el primer párrafo del artículo $4^{\circ}$ del mismo texto constitucional vigente reconoce explícitamente el Derecho Fundamental de las personas al Medio Ambiente sano, para enseguida reconocer también el Derecho Fundamental al Agua potable $y$ al saneamiento. ${ }^{(8)}$

En el ámbito internacional, la Asamblea General de Naciones Unidas aprobó la Declaración sobre los Derechos de los Pueblos Indígenas el 17 de septiembre de 2007. La Declaración reconoce los derechos colectivos de los

(8) El comité DESC OG 15, ha establecido que: "Ios Estados parte deberían garantizar un acceso suficiente al agua para la agricultura de subsistencia y para asegurar la supervivencia de los pueblos indígenas". En relación con estos últimos, se conmina a los Estados para que faciliten los recursos que les permitan a las comunidades planificar, ejercer y controlar su acceso al agua". 
pueblos indígenas, incluyendo su derecho a la libre determinación y los derechos a sus tierras, territorios y recursos. Así, por primera vez, la ONU reconocía derechos de los pueblos indígenas. Pero aún en 2018, el gran desafío sigue siendo que los estados las pongan en práctica y contribuyan a la mejora de la vida de los pueblos indígenas del mundo. ${ }^{(\mathbf{9})}$ Siendo entonces el tema de los Derechos Fundamentales de los pueblos indígenas de un interés creciente en el ámbito internacional, se ha ido poniendo de relevancia de modo gradual en los últimos tiempos. Así, la producción normativa y jurisprudencial es relativamente reciente si se la compara con otros asuntos de Derechos Humanos, a pesar de la innegable y profunda deuda histórica de las sociedades iberoamericanas y también otras muchas del mundo, guardan para con los pueblos indígenas.

Paradójicamente, el asunto de los derechos de los pueblos indígenas vuelve a ganar importancia en el contexto de la creciente presión por la tierra y los territorios indígenas, ${ }^{(10)}$ causado por un modelo de "desarrollo" basado en la explotación ilimitada de los recursos naturales que algunos autores han caracterizado como el paso del llamado "consenso de Washington" al "consenso de las commodities"(11) basado en la exportación de bienes primarios a gran escala, entre ellos, hidrocarburos (gas y petróleo), metales y minerales (cobre, oro, plata, estaño, bauxita, zinc, entre otros), productos alimenticios (maíz, soja y trigo) y biocombustibles. Este modelo, que busca sobre todo el crecimiento del producto interno bruto, se presenta frecuentemente como una oportunidad

(9) En los últimos años, las Naciones Unidas también han establecido tres importantes mecanismos destinados a proteger los derechos de los pueblos indígenas y la promoción de sus intereses. Observando su complementariedad con el Convenio 169 de la OIT sobre Pueblos Indígenas y Tribales de 1989 y se realiza un análisis crítico de las funciones de los principales mecanismos internacionales de derechos humanos dedicados a la protección de los pueblos indígenas, a saber, la Relatora Especial sobre los derechos de los pueblos indígenas y el Mecanismo de Expertos sobre los derechos de los Pueblos indígenas establecido por el Consejo de Derechos Humanos y el Foro Permanente para las Cuestiones indígenas que prestan asesoramiento al Consejo Económico y Social de las Naciones Unidas. BURGER, Julian. Óp. Cit.

(10) Para una explicación sobre tierras y territorios indígenas en el caso mexicano, véase a LÓPEZ, Francisco. (2015). La Tierra no se Vende. Sumariamente, sostiene dicho autor que uno de los derechos fundamentales de los pueblos indígenas, inherentes a su calidad de pueblos, es el de la libre determinación, expresado como autonomía. Y como parte esencial de la misma, el control de su territorio y los recursos naturales en ellos existentes. Por eso las referencias a la protección de las tierras indígenas, la conservación y el mejoramiento de su hábitat, así como el acceso y disfrute preferente de los recursos naturales de lugares que habitan y ocupan, debe entenderse en su conjunto como derecho al territorio; más cuando la legislación internacional expresa claramente que el concepto de tierra abarca el de territorio y que éste cubre la totalidad del hábitat de las regiones que los pueblos indígenas ocupan o utilizan de alguna manera.

(11) "Utilizamos aquí el concepto de commodities en un sentido amplio, como productos indiferenciados cuyos precios se fijan internacionalmente y no requieren tecnología avanzada para su fabricación" (y/o extracción y procesamiento). SVAMPA, Maristella. (2013). "Extractivismo en América Latina y el consenso de las commodities". El Correo de la Diáspora Latinoamericana. Recuperado en: http://www. elcorreo.eu.org/Extractivismo-en-America-Latina-y-el-Consenso-de-los-Commodities?lang=fr 
para las comunidades indígenas marginadas, ${ }^{(12)}$ pero sus resultados - como lo demuestran los indicadores socio-económicos - parecen beneficiar sobre todo al sector empresarial, tanto nacional como transnacional y no a las comunidades indígenas en las que se asientan territorialmente los proyectos extractivos. ${ }^{(13)}$

Pasados ya más de 10 años de la Declaración de las Naciones Unidas sobre los Derechos de los pueblos indígenas, valdría preguntarse: ¿Por qué y para qué una Declaración específica, si en el estado nación de tradición occidental y monista todos somos supuestamente libres e iguales? Primero, por la larga herencia de opresión de los pueblos indígenas a cargo de las poblaciones dominantes. Y luego, también por las serias dificultades para que las comunidades indígenas, tanto individual como colectivamente, hagan valer sus derechos constitucionales y los instrumentos internacionales más o menos a su alcance.

Sabiendo que la Declaración de la ONU sobre los Derechos de los Pueblos Indígenas o su réplica Americana no son nuevas Convenciones, Tratados o Protocolos, por lo que no son objeto de una ratificación formal, y que desde una perspectiva positivista bien pueden ser vistas como"no vinculantes" para los Estados; sin embargo hay al menos tres razones fundamentales por las cuales estos derechos "especiales" no pueden ser negados, mientras que los pueblos y comunidades indígenas bien las pueden considerar como herramientas importantes en la defensa de sus Derechos Fundamentales. A saber: todos esos derechos de las Declaraciones son respaldados por otros instrumentos internacionales ya ratificados por muchos Estados. Segundo, porque las Declaraciones son legítimas en la medida que involucraron en su consulta y redacción a una gran cantidad de actores indígenas y no indígenas en muchos países. Tercero, porque son instrumentos con amplio soporte en el concierto de la comunidad internacional. Dice la citada Declaración de la ONU en su artículo 3:

(12) "En el caso concreto de México, no se puede pretender que las violaciones a los derechos de los pueblos indígenas fueron "descubiertas" recientemente - al contrario, el relato de Bartolomé de las Casas "Brevísima relación de la destrucción de las Indias" puede ser considerado como el primer informe sobre violaciones de derechos humanos en América Latina, si no en el mundo. Además, en el contexto mexicano, el descontento de los pueblos indígenas sobre la manera en que "los gobernantes" les trataron y les tratan todavía, ha sido un factor clave en dos eventos de fundamental importancia histórica, la lucha por la Independencia (1810-21) y la Revolución mexicana 1910-20". (JARAB. J. (2018). Los Derechos de los Pueblos Indígenas en México, una mirada desde el Sistema de Naciones Unidas. Oficina en México del Alto Comisionado de Naciones Unidas para los Derechos Humanos. México, Primera edición. Pág. 9.

(13) "La precariedad en las condiciones de vida de la población indígena en México ha sido sistemáticamente mayor a la de la población no indígena. Aun en la actualidad, las personas que pertenecen a los pueblos originarios concentran diversos rasgos de desventaja social que las mantienen en una situación de rezago respecto al resto de la población. Muestra de ello es que, de acuerdo con las estimaciones de pobreza elaboradas por el CONEVAL, el porcentaje de población hablante de lengua indígena (HLI) que se encontraba en pobreza en 2012 casi duplicaba al de la población no hablante (76.8 frente a 43.0 por ciento) y el de población en pobreza extrema fue casi cinco veces mayor (38.0 frente a 7.9 por ciento)". CONSEJO NACIONAL DE EVALUACIÓN DE LA POLÍTICA SOCIAL (CONEVAL). La Pobreza en la población Indígena de México 2012. Pág. 12. Recuperado en: https://www.coneval.org.mx/Informes/ Coordinacion/INFORMES Y PUBLICACIONES PDF/POBREZA POBLACION INDIGENA 2012.pdf 
"Los pueblos indígenas tienen derecho a la libre determinación. En virtud de este derecho determinan libremente su condición política y persiguen libremente su desarrollo económico, social y cultural". (14)

Además, otros artículos también hacen referencia al ejercicio de este Derecho, que es tan importante porque resulta ser clave para el acceso a todos los demás, desde los económicos, sociales y culturales hasta los civiles y políticos. Así, la Libre Determinación parece el mejor camino para que los problemas que enfrentan los pueblos indígenas se resuelvan desde su propia visión. En este contexto, cabe mencionar la institucionalidad que debe desarrollar la autoridad pública para fomentar y respaldar la libre determinación, donde en los hechos se precisa con urgencia de un cambio de paradigma donde el cambio indudablemente pasa por la manera en que las autoridades se interrelacionan con los pueblos y comunidades indígenas.

Dos de los principios rectores de la Declaración son la prohibición de la asimilación forzada y el derecho de decidir sobre el propio modelo de desarrollo - y esto debería de ser el punto de partida en la relación entre las autoridades y los titulares de Derechos indígenas ${ }^{(15)}$. En el discurso público, la relación entre autoridades y comunidades indígenas, o el asunto de desarrollo de estas comunidades, sigue frecuentemente identificada únicamente con la consulta o mejor dicho- con el consentimiento.

Esto es por un lado entendible pues es cierto que la consulta puede ser una herramienta para asegurar la implementación de los demás derechos y que puede ser un instrumento de empoderamiento de las comunidades. Por otro lado, hay que decir que ésta herramienta también tiene sus límites; puesto que a la vez puede ser un instrumento de división al interior de los grupos indígenas y sus comunidades. La explicación reside en que no se pueden cargar todos los problemas estructurales, muchas veces históricos, a un proceso de consulta específico; y sobre todo a que existen realidades cada vez más complejas, y muchos asuntos que necesitan respuestas integrales o sistémicas si se prefiere.

Entonces, no es factible ni deseable reducir toda relación entre autoridades de distinto nivel y las comunidades indígenas en la mera consulta, cuando además la consulta como tal puede ser vista como un proceso unidimensional o utilitario, con el mero objetivo de aprobar lo que ya se decidió, desde un esquema "de desarrollo" de arriba hacia abajo.

\footnotetext{
(14) Declaración de la ONU sobre los Derechos de Los Pueblos indígenas. Asamblea General, 13 de septiembre de 2007. En http://www.un.org/esa/socdev/unpfii/documents/DRIPS es.pdf

(15) Son ideas ya propuestas por el primer relator de la ONU en materia de pueblos indígenas, Rodolfo Stavenhagen, a fines del siglo $\mathrm{XX}$, pero que siguen siendo perfectamente válidas hoy en día. Véase, por ejemplo: STAVENHAGEN, Rodolfo, 1992. “Los Derechos Indígenas, algunos problemas conceptuales", en: Nueva Antropología, Vol. XIII, México.
} 
Entonces, hay que insistir en que no se puede obtener el consentimiento -que es el objetivo de los procesos de consulta- sin que ésta sea verdaderamente previa, libre, informada, culturalmente adecuada y de buena fe. Ya esto parece un desafío, porque la gran parte de consultas no fueron ni son previas y había fuertes dificultades también con los demás criterios fijados por el estándar de la consulta, a saber: libre, informada, de buena fe, y con el objeto de obtener el consentimiento. Las autoridades tienen que reconocer y abordar también el nivel estructural que, hoy por hoy, persiste y complica el contexto en el cual se desarrollen las consultas: las desigualdades de poder político y económico -la persistente marginación de las comunidades indígenas, la falta de un verdadero acceso a los derechos económicos, sociales y culturales, la poca participación política, las dificultades de acceso a la justicia, así como los riesgos que viven las y los defensores de derechos indígenas-.

Las respuestas a estos desafíos no puede ni debe venir, nuevamente, desde el poder ya sea fáctico o constituido legalmente, sino que deben ser construidas contando con las propias comunidades, o aún mejor, basadas en sus propuestas y mediante un diálogo intercultural. ${ }^{(16)}$ Es importante destacar que se precisa un dialogo intercultural que pase por intentar entender al otro, escuchar, y construir propuestas en común como parte de la construcción de una política de estado transversal, unas relaciones institucionales y un marco jurídico plural. $Y$ aunque aparecen muchas dificultades en dicho diálogo intercultural, parece el mejor camino a seguir, pues las otras alternativas son inaceptables en un estado democrático, social y de Derecho, como el que en el discurso oficial pretendiera ser el Estado mexicano.

De manera que resulta muy dudoso que los avances en las normas y políticas nacionales e internacionales hayan ido al mismo ritmo que los avances en las realidades que enfrentan día a día las personas y los pueblos indígenas para exigir y garantizar derechos tan importantes como el de su auto-adscripción, el derecho al disfrute colectivo de sus territorios y recursos naturales o a su cultura y conocimientos ancestrales. Y es ahí donde el derecho a la consulta y el consentimiento previo, libre e informado adquiere especial relevancia, pues si bien no es un derecho sustantivo, sí que es una herramienta básica que lleva a la implementación de los demás derechos sustantivos, lo que genera un equilibrio en el diálogo y la participación que permite identificar riesgos y generar acuerdos, pero sólo cuando es implementada de forma adecuada.

Así, la consulta no debe ser tenida como un trámite para cumplir con una lista de requisitos formales. La consulta representa una oportunidad real de generar

(16) Véase al respecto la idea de dialogo intercultural que parte de una realidad multicultural no reconocida a nivel legal e institucional en: PASILLAS, Enrique. 2018. "Multiculturalismo y derechos fundamentales en el noroeste de México: El caso de la tribu yaqui", Estudios Fronterizos, Vol.19, 2018. Recuperada en: http://ref.uabc.mx/ojs/index.php/ref/article/view/658 
confianza inter partes en contextos e intereses muy diferentes para buscar espacios donde las partes puedan ser beneficiadas realmente, sin demagogia desarrollista. El hecho de que los gobiernos de los diferentes Estados-nación reconozcan y asuman la obligación de realizar estas consultas es un paso positivo, pero notoriamente insuficiente. Aún existen muchos aspectos urgentes para fortalecer el adecuado cumplimiento de este derecho de los pueblos indígenas que resulta además una clara obligación internacional para Estados. De manera que es necesario evitar que la consulta sea usada de mala fe y que, en lugar de abrir espacios de diálogo intercultural, resulte en la fragmentación de las comunidades indígenas y en un aumento de conflictos entre y adentro de ellas. ${ }^{(17)}$ Así, la correcta interpretación y aplicación de los diferentes criterios relacionados a los procesos de consulta es fundamental y los requisitos de que sean previas, libres, informadas, culturalmente adecuada y de buena fe, responden a una lógica formal, pero también práctica.

\section{Extractivismo y despojo de recursos naturales}

Pese al discurso constitucional e institucional de los diferentes gobiernos en México y en otros países del mundo, los pueblos indígenas son víctimas históricas de todo tipo de discriminación y despojo por una serie de razones que van desde el racismo histórico abierto o encubierto, hasta la codicia extractiva del capital local y foráneo. En dicho contexto, las luchas indígenas de las pasadas décadas en México -y en general en Iberoamérica- se encuentran marcadas por los nuevos rumbos que el "sistema- mundo" de corte liberal-capitalista (caracterizado por Wallerstein, entre otros), ha tomado, para entrar en una nueva fase económica que diversos analistas han denominado como "acumulación por desposesión" (HARVEY, David. 2005).

De acuerdo con estas tesis, una vertiente importante del capital internacional y sus ramificaciones locales, se enfocó durante los años recientes, a despojar a los pueblos del mundo, en especial a los pueblos originarios, de sus riquezas naturales. Aguas, bosques, minas, tierras, plantas, animales, así como saberes ancestrales y conocimientos asociados al uso y disfrute común, están perdiendo el carácter de bienes comunes que por siglos han mantenido para beneficio de la humanidad, convirtiéndose en propiedad privada y en mercancías, lo que representa sin duda un nuevo colonialismo. Los pueblos lo saben, y por eso

(17) "Nuestra Oficina ha documentado varios procesos de consulta en la república, incluyendo proyectos que afectaron los derechos de las comunidades zapotecas en Oaxaca, de los yaquis en Sonora, de los otomís en el Estado de México y Puebla, o de los mayas en Campeche, entre otros. Algunos de estos casos cuentan con recomendaciones de la CNDH o con sentencias judiciales, incluso de la SCJN. En todos estos procesos, hemos podido documentar ciertos patrones de dificultades relacionadas al dialogo intercultural y los problemas que pueden surgir o exacerbarse si los procesos no son implementados de manera correcta. Sobre todo, hemos observado los efectos de contraproducentes que resultan si la consulta padece de buena fe o tiene como efecto u objetivo dividir a las comunidades indígenas o de exacerbar las divisiones y tensiones internas que ya existen" ( JARAB, Jan. Óp. Cit. Pág. 26). 
lo resisten y luchan por liberarse de él, ${ }^{(18)}$ donde los movimientos indígenas en México se expresan sobre todo en espacios regionales, esto a pesar de que cada vez más, sus demandas adquieren carácter nacional e internacional. ${ }^{(19)}$

En cuanto al despojo de recursos naturales en perjuicio de los territorios indígenas ancestrales, podemos decir que para 2015 el mundo conoció un número aproximado de 1,500 conflictos socio-ambientales documentados. Centrándonos en Iberoamérica, la mitad de dichos conflictos sucedía en el entorno de los pueblos indígenas, que están frecuentemente situados en las denominadas: "fronteras de la extracción" (MARTíNEZ, Joan. 2015). La situación descrita se puede ver en todos los frentes de resistencia indígena en las Américas: en las luchas de los pueblos originarios que defienden su territorio y sus recursos naturales y por lo mismo, se oponen a las grandes obras de infraestructura (llamadas eufemísticamente megaproyectos o"proyectos de desarrollo") que destruyen sus modos de vida ancestrales y también la naturaleza. Son estos pueblos indígenas los mismos que defienden el maíz nativo o a las abejas autóctonas y que se oponen a los transgénicos, pero también son los que defienden el agua de un río para ellos sagrado, ${ }^{(20)}$ como los Yaquis; porque saben que en ello les va la vida, dado el deterioro ambiental y social que el nuevo extractivismo genera.

\section{Lucha Yaqui}

En el estado de Sonora, que ocupa una larga franja litoral del noroeste de México, con una superficie equivalente al $9.15 \%$ del territorio del país (más o menos equivalente a la superficie de Austria y Serbia, por ejemplo), habitaban 2,850,333 personas en 2015 (Instituto Nacional de Estadística y Geografía -INEGI-). (21) Dentro de dicho territorio, viven desde tiempos ancestrales 9 pueblos indígenas originarios, ${ }^{(22)}$ que en conjunto suman unas 138 mil personas, lo que representa alrededor del $5 \%$ de la población total del estado. De ellos, unos 51 mil son Yaquis. (ZARATE, José. 2016: 9).

(18) LÓPEZ, Francisco. S/f. En: http://www.lopezbarcenas.org/escrito/pueblos-indigenas-y-megaproyectos-en-mexico-las-nuevas-rutas-del-despojo);

(19) LÓPEZ, Francisco. S/f. Los Movimientos Indígenas en México, Rostros y Caminos, en: www. lopezbarcenas.org/escrito/los-movimientos-indigenas-en-mexico-rostros-y-caminos-1).

(20) "Consideramos al río como un ser vivo, no como un conducto o un canal. Si deja de tener escurrimientos, lo dejas en agonía y condenado a la muerte. No solo el yaqui requiere esa agua para consumo propio, no existimos solo los humanos, también existen los animales y el bosque, además de un inframundo. El agua conecta al yaqui con el río y el espacio. Es un portal, si se le pudiera llamar así. Pero hablando desde el punto de vista biológico, se daña el ciclo hídrico, la humedad ambiente, las recargas al subsuelo y al microclima que alimenta mezquites, cactus, a nosotros y al subsuelo". Declaración Pública de Mario Luna Romero, Vocero de la Autoridad Tradicional Yaqui, 2016.

(21) www.cuentame.inegi.org.mx

(22) "Pueblos Indígenas" en términos de colectivos humanos que se auto identifican como una comunidad originaria en el contexto de un estado nacional (Convenio 169 de la OIT, Declaración de las Naciones Unidas sobre los Derechos de los Pueblos Indígenas de 2007, Sistema Interamericano de Derechos Humanos (Comisión y Corte IDH). 
En consonancia con la situación nacional, los pueblos indígenas representan el grupo social con mayor rezago en Sonora, como sucede en el resto del país. ${ }^{(23)}$ También, como ocurre a nivel nacional, "armonizada" su Constitución política local con la nacional, el estado de Sonora se reconoce como un estado pluricultural, que está fundado en sus pueblos originarios, ${ }^{(24)}$ a los que deberá poner especial atención en sus demandas (LUQUE, Et. Al. 2012: 55).

Hiaki-Yoémem, es un autónimo que significa simplemente "la gente" (intentando llevar la fonética de la lengua yaqui -hiaki nooki (ZÁRATE, José. 2016: 8)- al español), o la Tribu Yaqui, también un autónimo en su modalidad de uso más extendido, cuyo territorio ancestral se encuentra justo en la cuenca del río Yaqui, el sur de Sonora, en el noroeste de México, ${ }^{(25)}$ representan un caso emblemático de sobrevivencia y empoderamiento pacífico aun en unas condiciones históricamente muy desfavorables de racismo, exclusión y guerra abierta o encubierta en su contra, de las que diversos autores han dado cuenta en diferentes momentos de la historia, puesto que las guerras étnicas en la región yaqui iniciaron en el temprano 1600 (MARTíNEZ, José J. 2004).

Desde entonces, los Yaquis se han involucrado esporádicamente en conflictos armados contra los diferentes invasores de sus territorios hasta llegar a su casi exterminio a finales del siglo XIX y principios del XX; ${ }^{(26)}$ resultado de una larga historia de conflictos violentos en su región, producidos en gran medida por el apoderamiento y dominio de la tierra y los recursos naturales por parte de blancos y mestizos.

(23) "La precariedad en las condiciones de vida de la población indígena en México ha sido sistemáticamente mayor a la de la población no indígena. Aun en la actualidad, las personas que pertenecen a los pueblos originarios concentran diversos rasgos de desventaja social que las mantienen en una situación de rezago respecto al resto de la población. Muestra de ello es que, de acuerdo con las estimaciones de pobreza elaboradas por el CONEVAL, el porcentaje de población hablante de lengua indígena (HLI) que se encontraba en pobreza en 2012 casi duplicaba al de la población no hablante (76.8 frente a 43.0 por ciento) y el de población en pobreza extrema fue casi cinco veces mayor (38.0 frente a 7.9 por ciento)". CONSEJO NACIONAL DE EVALUACIÓN DE LA POLÍTICA SOCIAL (CONEVAL). La Pobreza en la población Indígena de México 2012. Pág. 12. Recuperado en: https://www.coneval.org.mx/Informes/ Coordinacion/INFORMES_Y_PUBLICACIONES_PDF/POBREZA_POBLACION_INDIGENA 2012.pdf

(24) "El Estado de Sonora tiene una composición pluricultural sustentada originalmente en los pueblos indígenas, que son aquellos que descienden de poblaciones que habitaban en el territorio actual del Estado al momento de iniciarse la colonización y que conservan sus propias instituciones sociales, económicas, culturales y políticas, o parte de ellas". Artículo 1, párrafo tercero. Constitución Política del Estado Libre y Soberano de Sonora, Boletín Oficial del Estado, 30-01-2017. Recuperada en: http://armonizacion.cndh.org.mx/Content/Files/sec03_A/constitucion/Constitucion_Son.pdf

(25) Los Yaquis-Yoemes son un grupo étnico del noroeste de México, del tronco uto-mexica, cuyo motherland o territorio ancestral abarcó antes de la colonización española toda la región de la cuenca comprendida entre los ríos Yaqui y Mayo, al norte del actual estado de Sinaloa y el sur del estado de Sonora.

(26) Para el caso particular de los Yaquis al inicio del siglo XX, véase a John Kenneth Turner, en México Bárbaro (1909). A Héctor Aguilar Camín, en La Frontera Nómada (1982) o a Taibo Il, Yaquis, Historia de una Guerra Populary de un Genocidio en México (2014). 
Después de la Revolución Mexicana, los Yaquis consiguieron la restitución de parte de sus territorios ancestrales en 1937, mediante un Decreto Presidencial bajo el gobierno del general Lázaro Cárdenas, además de cierta autonomía administrativa en 1939. Así, en 1940, mediante un Decreto Presidencial, ${ }^{\text {(27) }}$ se restituyeron algunas tierras de las que habían sido despojados los Yaquis a lo largo de la historia independiente de México. Estos Decretos reconocían a los Yaquis el uso y disfrute colectivo de la margen derecha del río Yaqui, con lo que perdieron los pueblos de Cócorit y Bácum, pero aun así se alcanzó una etapa de cierta paz desconocida en la región durante las décadas anteriores (LERMA, Enriqueta. 2014: 255). Pero esos derechos ancestrales ya reconocidos, han sido luego muy afectados en recientes décadas por la deriva violenta y autoritaria de la actual crisis mexicana, así como por ese nuevo extractivismo solapado desde los diferentes estratos del Estado (LUQUE, Et. Al. Óp. cit.), (MORENO, J.L. 2014), (LERMA, Enriqueta. 2014); además de la criminalización abierta o encubierta de las autoridades tradicionales y los liderazgos yaquis (GILLY, Adolfo. 2015), (LÓPEZ, Francisco. 2014).

El Yaqui solía en el pasado ser un caudaloso río (al que el jesuita Pérez de Ribas comparaba en el siglo XVII con el Guadalquivir, en Andalucía) del noroeste de México. Cruza al Estado de Sonora de norte a sur, bajando de la Sierra Madre Occidental y serpenteando hasta desembocar cerca del puerto de Guaymas. El río Yaqui nace nominalmente de la confluencia de los ríos Bavispe y Papigochi, en las estribaciones de la Sierra Madre Occidental, en el territorio del vecino estado de Chihuahua, para desembocar en el Golfo de California, cerca del poblado de San Ignacio Rio Muerto, en pleno Valle del Yaqui. Tiene una longitud de 410 km, aunque si se considera junto con sus afluentes, el Sistema Yaqui-Papigochi alcanza una longitud de $1.050 \mathrm{~km}$. Su curso se encuentra interrumpido por varias represas de uso hidroeléctrico, que crean importantes embalses como los de la presa El Novillo (Plutarco Elías Calles), Lázaro Cárdenas (Angostura) y Álvaro Obregón (El Oviáchic). Además de las hidroeléctricas, el río proporciona agua para la irrigación de la zona agrícola del Valle del Yaqui y Vicam, y sus aguas se aprovechan para regar extensos terrenos que forman el valle del Yaqui, de unas 450 mil hectáreas.

Transcurrido casi un cuarto del siglo XXI, las nuevas luchas yaquis suceden desde 2010, pues la tribu, entre otros colectivos sociales de la región sur de Sonora, se ha enfrentado abiertamente al gobierno de dicho Estado por su directa responsabilidad en un "mega proyecto" de índole extractiva: el desvío de 75 millones de metros cúbicos de agua de la cuenca del río Yaqui a la cuenca del río Sonora. ${ }^{(28)}$ Así, la renovación de un conflicto antiguo entre las autoridades locales

(27) Diario Oficial de la Federación DOF: 27 de octubre de 1937, 10 de junio de 1938 y 15 de septiembre de 1940 .

(28) RESTOR, Macrina. (2015), “Plática sobre las comunidades Yaqui”. Febrero. En: www.colson.mx 
y federales con la Tribu Yaqui tiene como marco una lucha por el agua ${ }^{\text {(29) }}$ que no es nuevo, pero que si reviste actualmente características diferentes a las históricas por las razones que a continuación se exponen. ${ }^{(30)}$

Como se ha dicho, se trataba en la especie del proyecto denominado "Acueducto Independencia", que va de la presa del Novillo, en la cuenca del río Yaqui, a la ciudad de Hermosillo, capital del estado, que es justo otra cuenca, la del río Sonora; lo que constituye de hecho un trasvase de agua entre cuencas diferentes que en principio no está recomendado ni permitido por las autoridades ambientales federales, que son las encargadas de su regulación. ${ }^{\left({ }^{31)}\right.}$ Entonces, el eje del conflicto entre el gobierno de Sonora y la tribu Yaqui fue la disputa legal y la movilización social contra el proyecto de trasvase del agua del río Yaqui entre 2010 y $2014 .^{(32)}$

Para algunos estudiosos del tema en la región, "los promotores principales de esa gran obra hidráulica fueron los sectores inmobiliario, de la construcción, comercial e industrial de Hermosillo" (MORENO J.L. 2015), la capital del estado de Sonora, con 884,273 habitantes en 2016 según el INEGI, donde se ve claramente la huella del extractivismo y del de despojo que se han caracterizado líneas arriba, mientras que el grupo opositor al proyecto lo integraron los agricultores del Valle del Yaqui, el llamado Movimiento Ciudadano por el Agua y la Tribu Yaqui, donde el conflicto por el agua lo marca las fuertes oposiciones sociales a la decadencia de un modelo de gestión hídrica denominado "agua de la nación" en su transición hacia el modelo mercantil-ambiental; ambos caracterizados por Aboites. ${ }^{\text {(33) }}$

En febrero de 2010, el gobierno de Sonora anunció públicamente la construcción de un acueducto desde la presa llamada "El Novillo" hasta la ciudad de Hermosillo, capital de Sonora, distante 150 kilómetros, con el discurso de llevar agua para uso doméstico a los habitantes de la ciudad. Pero tal decisión tomada carecía de consenso social y era producto de decisiones unilaterales, (en el mejor de los casos autoritarias, y corruptas en el peor), por lo que la obra fue rechazada

(29) El acceso al agua era casi tan importante como la tierra misma. Los grandes agricultores disponían de abogados para obtener derechos al uso del agua en los principales ríos que otorgaba el gobierno federal, y las conexiones políticas para lograr una participación efectiva en el control de los ayuntamientos..." (AGUILAR, 1985, citando a Voss, Stuart, 1971).

(30) Ya en 1891, el "notable" Ramón Corral, quien fuera gobernador de Sonora, reconocía la importancia del agua en la región Yaqui, dado que "los ayuntamientos tenían a su cargo la administración de las aguas de la comunidad..."'lo cual los pone en actitud de influir muy poderosamente y de manera muy directa en el bienestar de sus propias localidades..." AGUILAR, ídem.

(31) ABOITES, Luis; y MORENO, J.L. (2015). “Despojo de agua en la cuenca del río Yaqui”, HermosiIlo, Historia Mexicana, El Colegio de Sonora Julio-Septiembre, 466-479.

(32) Sostiene Moreno (2014), que el conflicto social se extiende también entre el gobierno y diferentes actores sociales de Sonora, como las asociaciones de agricultores, los municipios de la región, los Distritos de Riego, los ambientalistas y señaladamente los Yaquis.

(33) ABOITES, Luis. (2009). La Decadencia del Agua de la Nación. Estudio sobre desigualdad social y cambio político en México. Segunda mitad del siglo XX. El Colegio de México. 
de inmediato por los agricultores del distrito de riego 041 del Rio Yaqui, pues consideraron que serían afectados y que existían otras alternativas para dotar de agua a la capital del estado. Luego, se sumaron al grupo opositor otros sectores del municipio de Cajeme y de otros Ayuntamientos de la región, así como los miembros de la tribu Yaqui.

Así, en agosto de 2010, las Autoridades Tradicionales de la Tribu Yaqui iniciaron un juicio ante el Tribunal Unitario Agrario del Distrito 35 con sede en Ciudad Obregón, Sonora, para paralizar y evitar la construcción del denominado "Acueducto Independencia". Reclamaban la restitución del 50\% de las aguas del río Yaqui, que les corresponden según el Decreto de dotación presidencial de 1940. Los Yaquis pedían también que se emitieran medidas cautelares urgentes en contra de las autoridades para que se abstuvieran de emitir cualquier acto o decreto en el que se involucraran los volúmenes de agua de la cuenca del rio Yaqui. ${ }^{(34)}$

Luego, ante la inefectividad de dicho procedimiento para paralizar las obras, los Yaquis interpusieron también una demanda de amparo ante un Juez de Distrito, presentada el 2 de agosto de 2010 por los Gobernadores Tradicionales Yaquis de Vicam y Pótam. La demanda se enderezaba contra la omisa o inexistente: "Manifestación de Impacto Ambiental"(35) de las obras del acueducto.

Pero la resistencia civil pacífica primero y la defensa legal después, no pudieron detener la construcción del acueducto ni la terminación de la primera etapa de la obra en 2012, que empezó pruebas y después el trasvase del agua del río en 2013, aunque las obras violaron diversas suspensiones obtenidas por los diferentes actores inconformes de sendos jueces federales, que fueron impotentes o incapaces de hacer cumplir sus determinaciones, no obstante estar facultados para hacerlo en términos de la Constitución y la Ley de Amparo en vigor, aún por medio del uso de la fuerza pública.

Así, el Juez de Distrito competente otorgó medidas cautelares en vía de Juicio de Amparo, denominadas "suspensión provisional", que comprendían a los ocho pueblos que conforman la Tribu Yaqui. Y no fueron las únicas suspensiones concedidas, pues las comunidades de regantes de los Distritos de riego de la cuenca del Yaqui también interpusieron diversos juicios de amparo que fueron obsequiadas con sendas suspensiones. Sin embargo, desobedeciendo todas las

(34) La Jornada, 4 de agosto de 2010.

(35) La Manifestación de impacto Ambiental (MIA), es un estudio técnico -científico, de carácter preventivo y de planeación, que permite identificar los efectos que puede ocasionar una obra o actividad sobre el medio ambiente, y señalar las medidas preventivas que minimicen dichos efectos negativos de la ejecución de dichas obras o actividades. Este estudio permite a la autoridad evaluar la factibilidad ambiental para la ejecución de proyectos de inversión industrial, de infraestructura, manufactura, comercios o servicios. Se entiende entonces que dicho estudio tiene que ser previo a la autorización de la ejecución de la obra, y no posterior. Ley General del Equilibrio Ecológico y la Protección al Ambiente (Artículo 28 al 35 Bis 3). 
suspensiones decretadas a favor de los quejosos, el gobierno de Sonora en ningún momento paralizó la licitación pública de las obras del acueducto proyectado. Y no solo eso, sino que adjudicó la construcción del acueducto. ${ }^{(36)}$

En respuesta, los días 20 y 21 de noviembre de 2010 se llevó a cabo en el pueblo Yaqui de Vícam el Primer Foro en Defensa del Agua, organizado por las Autoridades Tradicionales yaquis y el Congreso Nacional Indígena. En el foro, se rechazó el creciente despojo y apropiación privada del agua y la construcción de acueductos y represas para "acapararla y venderla". A fines de noviembre, se estableció también una alianza entre El Movimiento Ciudadano por El Agua, la tribu Yaqui y el gremio minero de Cananea en defensa del agua, cuyo propósito fundamental era:

"la defensa del Estado de Derecho, entendido este como la garantía de que en el respeto a nuestros principios constitucionales se encuentran las posibilidades del bienestar general, la gobernabilidad y la paz social" (MORENO, J.L. 2014). ${ }^{\text {(37) }}$

Posteriormente, la Suprema Corte de Justicia de la Nación (SCJN) determinó en mayo de 2013 en una sentencia que ahora se considera un como precedente fundamental en la lucha indígena por el respeto a sus Derechos Fundamentales en México, ${ }^{(38)}$ que habían sido efectivamente violados sus Derechos a la Consulta Previa (MORENO, J.L., 2014). La Corte resolvió que el acueducto violaba el Derecho del pueblo Yaqui a la Consulta, que "debería hacerse de manera informada, de buena fe y en aras de obtener su consentimiento". ${ }^{(39)}$ Tal protección se traducía en una orden directa de la Corte a diversas autoridades federales responsables, para realizar una consulta a la tribu vinculada a la Manifestación de Impacto Ambiental del Acueducto, -el motivo de la controversia concreta-, que obviamente no podía ya ser previa,

(36) Un consorcio compuesto por 16 empresas de la región, denominado Exploraciones Mineras del Desierto, que hizo una propuesta por 2,443 millones de pesos, proyectando un tiempo de ejecución de las obras de 543 días. MORENO, J.L. óp. cit, pág. 72.

(37) Ídem. Pág. 76.

(38) "Nuestra Oficina ha documentado varios procesos de consulta en la república, incluyendo proyectos que afectaron los derechos de las comunidades zapotecas en Oaxaca, de los yaquis en Sonora, de los otomís en el Estado de México y Puebla, o de los mayas en Campeche, entre otros. Algunos de estos casos cuentan con recomendaciones de la CNDH o con sentencias judiciales, incluso de la SCJN. En todos estos procesos, hemos podido documentar ciertos patrones de dificultades relacionadas al dialogo intercultural y los problemas que pueden surgir o exacerbarse si los procesos no son implementados de manera correcta. Sobre todo, hemos observado los efectos de contraproducentes que resultan si la consulta padece de buena fe o tiene como efecto u objetivo dividir a las comunidades indígenas o de exacerbar las divisiones y tensiones internas que ya existen" (J. JARAB, J. Cit. Pág. 26).

(39) Amparo en Revisión 631/2012, sentencia de 8 de mayo de 2013. Suprema Corte de Justicia de la Nación (SCJN). En el caso del Acueducto Independencia, La Corte (SCJN) ejecutó una facultad llamada "de atracción" de ciertos asuntos de especial relevancia o trascendencia prevista en la Ley de Amparo, y así atrajo el Juicio correspondiente, en el cual concedió "el amparo y protección de la Justicia de la Unión", (rezan las sentencias que conceden el amparo), a la Tribu Yaqui. 
visto que el acueducto en ningún momento suspendió su operación desde la finalización de la obra. ${ }^{(40)}$ Ya dictada la sentencia de Amparo a favor de la tribu Yaqui, las autoridades federales en materia ambiental solicitaron a la Corte una indebida "Aclaración de Sentencia", y contra la buena práctica judicial estatuida por la misma Corte en el sentido de no analizar juicios ya concluidos, la aclaración fue extrañamente obsequiada, donde la Primera Sala resolvió sustancialmente como sigue en lo que interesa: "...esta primera Sala estima conveniente resaltar la diferencia entre consulta y consentimiento, pues sin perjuicio del hecho de que toda consulta debe perseguir el consentimiento, en algunos casos, su ausencia, puede que no impida a la autoridad decretar las acciones correspondientes, lo cual dependerá del nivel de impacto que tendrá la operatividad del Acueducto Independencia sobre la comunidad o grupo indígena, debiéndose ponderar los intereses sociales en juego, esto es tanto de los afectados como de los beneficiados con la obra, quedando en aptitud las autoridades correspondientes a decretar, en la medida de sus facultades, las acciones correspondientes para resarcir o aminorar las eventuales afectaciones que deriven de la operatividad del proyecto sobre la cuenca a manera de garantizar la subsistencia de la tribu a la que se concede el amparo a manera de que sea escuchada para efectos de la operación (no construcción) del acueducto."(41)

Una aclaración que como se puede ver no fue muy clara, pero que el gobierno federal usó para justificar la realización de una consulta ex post a la Tribu Yaqui sin detener la operación del acueducto. Así, sentando un precedente muy negativo, la sentencia de la Corte inexplicablemente desvinculó el consentimiento de la Consulta Previa, libre e informada. Y se abstuvo también de ordenar en su sentencia y en la posterior aclaración de la misma, la suspensión de la operación del acueducto, declarando que había que esperar a los resultados de una consulta sine die. De modo que el acueducto no interrumpió su funcionamiento, ni el gobierno local ni el federal acataron en los hechos la sentencia protectora. Tiempo después, en agosto de 2014, las Autoridades Tradicionales de la tribu solicitaron al gobierno federal (SEMARNAT), la realización de un peritaje antropológico que determinara las afectaciones que sufriría la tribu con motivo de la operación del acueducto. Dicho peritaje fue elaborado por el INAH ${ }^{\mathbf{( 4 2 )}}$ a petición de SEMARNAT, ${ }^{\mathbf{( 4 3 )}}$ usando una metodología interdisciplinar ad-hoc, y fue hecho público en $2015 .{ }^{(44)}$ En síntesis, el peritaje concluyó que:

(40) El acueducto fue inaugurado en diciembre de 2012 por el C. Presidente de la República sin estar formalmente concluido, e inició operaciones de trasvase en abril de 2013.

(41) Aclaración de Sentencia del Amparo en Revisión. Expediente: 631/2012, de 7 de agosto de 2013. https:/www.sitios.scjn.gob.mx/codhap/sites/default/files/engrosepdf_sentenciarelevante/12006310.002-1712_0.pdf).

(42) Instituto Nacional de Antropología e Historia: "Peritaje Antropológico respecto del impacto social y cultural por las obras del acueducto independencia" Recuperado en: https://revistas.inah.gob.mx/ index.php/rutasdecampo/article/download/7440/8280

(43) Secretaria del Medio Ambiente y Recursos Naturales.

(44) INAH, 2015. "Peritaje Antropológico", Diario de Campo, mayo. 
"...para atender la demanda Yaqui, se debe de respetar el caudal mínimo ecológico del rio, lo cual implica un manejo sostenible del bien hídrico dentro de límites ecológicos y justos, entendiendo al bien hídrico como insustituible, de uso compartido, y sustentando en una regulación comunitaria para su preservación, ya que de esto emana el soporte del nicho eco sistémico directo, lo cual es valorado y representado como cultura, o precisamente como cultura del agua, lo cual debe llevar a la eliminación, cancelación o cierre del acueducto." ${ }^{\prime(45)}$

Al hilo de lo expuesto, valga recordar que en la Jurisprudencia del Sistema Interamericano de Derechos Humanos, $(\mathrm{SIDH})^{(\mathbf{4 6})}$ la Consulta debe ser Previa, Libre, Informada, de Buena Fe y con el objeto de conseguir el consentimiento. Y no es una facultad discrecional, sino una obligación ineludible del Estado, aunque ciertamente no de las empresas vinculadas a las obras o "mega" proyectos de nversión. ${ }^{(47)}(48)$

(45) PADILLA, Raquel. (2015). “Peritaje Antropológico, Impacto social y cultural por la operación del acueducto independencia". Diario de Campo, mayo de 2015, Instituto Nacional de Antropología e Historia, INAH. México.

INAH, 2015. “Peritaje Antropológico: Impacto social y cultural por la operación del Acueducto Independencia". Diario de Campo, mayo.

(46) Organización de Estados Americanos (OEA). Corte Interamericana CIDH. S/f. Pueblos Indígenas y Tribales. Cuadernillo de Jurisprudencia de la Corte Interamericana de Derechos Humanos. Número 11. Recuperado en: http://www.corteidh.or.cr/sitios/libros/todos/docs/indigenas.pdf

(47) Es público un compendio de información presentado por la coalición de organizaciones de la Sociedad Civil al grupo de Trabajo sobre empresas y Derechos Humanos de la ONU. En dicho informe, llamado México: empresas y derechos humanos, (2016) se indica que los principales abusos cometidos son la falta de consulta previa, libre, informada y culturalmente adecuada, de debida diligencia y la proliferación de megaproyectos. Empresas trasnacionales y nacionales han quedado evidenciadas ante la Organización de las Naciones Unidas (ONU) por violación a los derechos humanos. El listado de más de 60 casos de violaciones a derechos humanos fue presentado por organizaciones no gubernamentales ante un equipo de trabajo del organismo internacional. Las compañías denunciadas son 99: 41 nacionales, 50 extranjeras y 8 del Estado. Entre las involucradas destacan Grupo Higa, Tradeco, Bimbo, Cargill, Monsanto, Grupo Carso y Grupo Bal, Grupo México, Minera Excellon, Petróleos Mexicanos. El documento, elaborado por más de 100 organizaciones defensoras de Derechos Humanos (entre ellas Centro de Derechos Humanos Miguel Agustín Pro Juárez, Centro Mexicano de Derecho Ambiental, Fundar Centro de Análisis e Investigación, Greenpeace México, Oxfam México, Serapaz, Servicios y Asesoría para la Paz, Proyecto de Derechos Económicos, Sociales y Culturales), precisa los casos de abuso a derechos humanos relacionados con actividades empresariales como minería (11), cementeras (5), hidrocarburos (9); producción de energía mediante hidroeléctricas y parques eólicos y abusos relacionados con los consumidores (8); construcción de infraestructura (9); agroindustria y forestal (6); maquilas y corredores industriales (4), y otras ramas productivas (8), además de empresas de seguridad privada, exportación ilegal de arma a zonas de conflicto y turismo.

(48) como erróneamente se establece, por ejemplo en la Ley de Energía Eléctrica y su reglamento, recientemente aprobados, y bajo cuyas condiciones se ha intentado justificar los parques eólicos que operan en el istmo de Tehuantepec en Oaxaca, sin que cuenten con la Consulta Previa ni el consentimiento de los pueblos indígenas afectados. CALERO, Sofia, (2015). Windpower and environmental conflicts in the global south, Evidence from the isthmus of Tehuantepec, México; Barcelona, en: https:// www.academia.edu/21564467/Wind_Power_and_ 
Tal vez sea por eso que tanto en Sonora como en el resto del país, diversos organismos empresariales como el Consejo Coordinador Empresarial, suelen pedir públicamente al gobierno que los efectos de las consultas a los pueblos indígenas sobre los proyectos en sus territorios no sean vinculantes, para que no"se obstruyan" los proyectos de inversión. Incluso, representantes de la multinacional Monsanto a propósito de los Juicios de Amparo promovidos por organizaciones indígenas mayas en contra de la introducción de soya transgénica en sus territorios, han llegado a declarar públicamente que "sería un mal precedente si se consulta a las etnias".(49)

Así las cosas, entre los retos más importantes para la sociedad y el Estado mexicano está el respeto a los derechos Fundamentales de los pueblos indígenas, señaladamente el respeto a la autonomía, a la consulta previa, y a propiedad social de la tierra, donde debe darse, desde luego, como ha establecido la Jurisprudencia de la Corte IDH, un carácter claramente vinculante al Derecho a la consulta y a su resultado, dejando atrás la idea tan extendida de que la Consulta Previa a los pueblos indígenas "paraliza" el desarrollo económico. Simular consultas "a modo", como se ha intentado hacer en el pasado para justificar el cumplimiento de las normas internacionales que no tienen desarrollo ni consecuencia en el ámbito interno, no tiene sentido ya ante la creciente conflictividad socio ambiental en todo el país, en especial en los territorios indígenas. Por lo expuesto se infiere entonces que la regla general debería ser que, si no hay un consentimiento derivado de una consulta previa, libre, informada, de buena fe y que cumpla los estándares internacionales, no puede haber proyectos de desarrollo o extracción posibles en los territorios de los pueblos indígenas.

\section{Análisis y conclusión}

Primeramente, hay que destacar el hecho de que, aunque Sonora es la entidad federativa del norte de México que cuenta con mayor diversidad étnica y cultural, carece de una normatividad que regule la interculturalidad, pues los grupos de poder son creadores o portadores de determinados arquetipos sobre lo que culturalmente es y debe ser Sonora. En la última década, su concepción ha pretendido consolidar la imagen de la entidad como el resultado del mestizaje de la sociedad criolla colonial, con ciertos sectores "indígenas", que racial y culturalmente permitían el engrandecimiento de una especie de "utopía ibérica de renacimiento en la América septentrional" (MANRIQUEZ y CASTRO. 2007).

Luego, está el tema del inicio de las obras del denominado "Acueducto Independencia", donde la conflictividad social latente en la región yaqui escaló y adquirió mayor relevancia, dado el reavivamiento de la vieja contienda entre la tribu y otros actores sociales en Sonora (MORENO J.L. 2014). La razón no era otra más que la ejecución de un "proyecto de desarrollo" consistente en las obras de

La Jornada Maya, 21 de octubre de 2015. 
un acueducto para el trasvase de agua desde la cuenca del río yaqui a la ciudad de Hermosillo, capital del estado, en un medio natural caracterizado por sus altas temperaturas durante la mayor parte del año y conocido geográficamente como Desierto de Sonora, donde el agua es un bien escaso y valioso.

Con este marco general, en la región Yaqui, coinciden por otra parte en señalar autores como SHIVA, Vandana. (2004), TOLEDO, Víctor (2015) o MARTíNEZ, Joan. (2015), que uno de los problemas más álgidos de nuestro tiempo en todos los países es la lucha por el control del territorio y los recursos naturales del planeta, en primer lugar el agua. ${ }^{(\mathbf{5 0 )}}$ Así, por un lado están quienes la consideran un Derecho Humano Fundamental, tal como aparece estatuido en el artículo $4^{\circ}$ de la Constitución Mexicana, y por otro, quienes piensan que es una mercancía como cualquier otra, susceptible por tanto de apropiación y comercio sin restricción posible alguna.

Una visión desde la Ecología Política ${ }^{(51)}$ que defienden Joan Martínez Alier y otros, sostiene que se trata de una tensión entre los distintos lenguajes de valoración con los que se juzga un conflicto distributivo en concreto. Así, realizar un análisis estructural de los conflictos, implicaría discurrir sobre la importancia que los contextos histórico, cultural y social tienen sobre la comprensión de la realidad y como esta interpretación se expresa a través del lenguaje. Partiendo de esa base, se puede entender que algunas comunidades apelen a valores ambientales para defender su entorno, otras a valores sociales o históricos como sus Derechos ancestrales o su condición de indígenas, y otras comunidades apelen a la sacralidad de la naturaleza.

El núcleo de la discordancia se halla en aquello que se puede medir bajo los parámetros del mercado (la crematística, aquello que se mide y se cuenta en dinero) y aquello que se mide con otros valores (la oikonomia, aquello que los griegos llamaron "valores reales". (ESPINOZA, 2012).

En México este patrón de problemas socio-ambientales tiende a expandirse y a repetirse por todo el país. No es la excepción la región yaqui, como ya había observado y anticipado el antropólogo Spicer (1994) a mediados del siglo pasado. En Sonora, concretamente, a fines del siglo anterior, el antiguo proyecto de la construcción del que luego sería denominado "Acueducto Independencia" consistía en un trasvase de agua de la cuenca del río Yaqui a la del río Sonora, y se concibió como un modo de llevar un flujo considerable de agua para uso no agropecuario (urbano e industrial) a la capital de Sonora, Hermosillo, en detrimento de agricultores y campesinos indígenas y mestizos (MORENO J.L. 2014). Por lo demás, no debería pasar por alto que es justamente el estado de Sonora, según

(50) Véase a: BARRY, Tom. (2015). Water Wars: water crisis destabilizing northern mexico as the yaqui lose major water battle in Sonora, Center for Internacional Policy, august, 2015. En: http://www. ciponline.org/images/uploads/publications/Water_Wars_TB_UPDATED.pdf

(51) Término por primera vez usado por el antropólogo Eric Wolff en 1972 para referirse al estudio transdisciplinar de los conflictos ecológicos distributivos. Después popularizado por otro antropólogo, Mac Netting. 
información oficial, una de las tres entidades federativas que en México albergan mayores concesiones mineras en su territorio, y también donde más problemas ambientales han ocasionados las compañías mineras presentes. ${ }^{(52)}$ (53) (54) Así, se sabe que las operaciones rutinarias de la industria minera provocan serios problemas sociales de salud e impactos ambientales. En casi todos los casos son sufragados por las comunidades locales que dependen de sus recursos naturales para subsistir.

Frecuentemente, los grupos indígenas son los más afectados por las operaciones mineras. Se estima que para 2020, de 60 a $70 \%$ de la producción de cobre, tendrá lugar en territorios indígenas. (MOODY, 2001, citado por ALFIE, 2015). De manera que a priori y sin profundizar el nivel de análisis, es posible decir que al preferir el uso industrial (señaladamente el minero) sobre el uso doméstico y agropecuario para el agua, el gobierno de Sonora y también el Federal se apartaron claramente en la región yaqui del mandato constitucional que sitúa al agua como un bien común y como un Derecho Fundamental amparado por el artículo $4^{\circ}$ de la Constitución. Esto, desde luego, concitó la contestación social en toda la región y en especial el repudio yaqui, pues para los miembros de la tribu el agua del rio no solo les da sustento vital, sino que es fuente de su identidad colectiva. ${ }^{(55)} \mathrm{O}$ en palabras de Vandana Shiva:

"...un choque entre dos culturas, una que ve el agua como algo sagrado, y considera su suministro como una obligación para preservar la vida, y otra que la considera una mercancía cuya propiedad y comercio son Derechos corporativos fundamentales" (Shiva, 2012).

Lo cierto es que la historia de las relaciones entre gobiernos y Yaquis fue siempre conflictiva y muchas veces sangrienta, pero siempre con origen en la apropiación de la tierra, y de manera más reciente, el agua.

(52) Justamente en 2014, siete municipios aledaños al río Sonora se vieron afectados por el mayor desastre ecológico minero en la historia reciente. Ese año, la mina llamada "Buenavista de Cobre", del consorcio llamado "Grupo México" derramó en el afluente 40 mil metros cúbicos de tóxicos y metales pesados. Vale decir también que a dos años de la tragedia ambiental, los pobladores aún exigen al Gobierno que limpie el caudal y que frene el daño ambiental ocasionado.

(53) MACÍAS, Samantha, (2016). “En México, el mayor número de conflictos mineros de AL: 80 socio-ambientales y 22 laborales", Sinembargo: http://www.sinembargo.mx/22-08-2016/3082109

(54) "La contaminación y daño en el río Sonora permite analizar los conflictos socio-ambientales desde la perspectiva de la justicia ambiental y la ecología política. En ambos casos, diversos actores se confrontan por un territorio frente a intereses empresariales o de Estado, en donde es sintomática la falta de equidad procedimental, geográfica y social en las concesiones otorgadas a las industrias mineras." ALFIE, Miriam. (2015), "Conflictos socioambientales: Ia minería en Wirikuta y Cananena", El Cotidiano, número 191, may-jun 2015, Universidad Autónoma Metropolitana, Unidad Atzcapotzalco, D.F. México. En http://www.redalyc.org/pdf/325/32538023011.pdf

(55) PADILLA, Raquel. (2015). “Peritaje Antropológico, Impacto social y cultural por la operación del acueducto independencia". Diario de Campo, mayo de 2015, Instituto Nacional de Antropología e Historia, INAH. México. 
Sin embargo, y pese a un entorno actual adverso, los Yaquis construyen ciudadanía y desde hace décadas, cuando renunciaron a la reivindicación violenta y realizan una lucha legal y pacífica contra el racismo, la discriminación y el despojo del agua que sufren, así como de los recursos naturales de sus territorios ancestrales.

Igualmente, la lucha de la tribu Yaqui, se plantea para el reconocimiento de sus Derechos Fundamentales ${ }^{(56)}$ a la autonomía, al medio ambiente sano, al agua potable y su saneamiento, a la consulta previa, libre, informada culturalmente adecuada y con el propósito de obtener su consentimiento o a reproducir su cultura, y su cuestionamiento y violación por todo tipo de actores estatales pero también no estatales. Así, podemos decir sin duda que la tribu Yaqui fue pionera en los temas de la autoconsciencia y la autonomía indígena en México, pues de ello dan cuenta desde diversos enfoques, autores como AGUILAR, Héctor. (1985), SPICER, Edward (1994), o HU, Evelyn (2016). Curiosamente, en esa lucha histórica contra la opresión y a favor de su cohesión cultural, los yaquis no encuentran ninguna contradicción entre ser autónomos y pertenecer a la vez a un Estado nacional, aunque sí cuestionan como parte de sus reivindicaciones históricas, como muchos otros pueblos indígenas de México, la falta de voluntad estatal para reconocerles como sujetos de derechos colectivos (LERMA, Enriqueta. 2014). Pero tienen una valiosa experiencia que construye ciudadanía a través de la interculturalidad y de digna lucha legal por el reconocimiento de sus Derechos ancestrales e históricos. ${ }^{(57)}$ Por lo demás, interesa destacar finalmente el acoso bien documentado de ciertos actores sociales en Sonora contra la lucha pacífica de la Tribu Yaqui "Ios más visibles enemigos del progreso" (MORENO, J.L. óp. cit. Pág. 317).

(56) Según el desarrollo jurisprudencial progresivo desplegado por los Tratados y Convenciones Internacionales suscritos por el estado mexicano, empezando por la Declaración Universal de Derechos Humanos de 1948, la Americana del mismo año, El Pacto Internacional de Derechos, o la creación del Sistema Interamericano de Derechos Humanos (Comisión y Corte) en 1968. Pero también el Acuerdo 169 de la OIT sobre Pueblos Indígenas y Tribales, la Declaración de las Naciones Unidas ONU sobre los Derechos de los Pueblos Indígenas, la Declaración Americana Sobre los Derechos Indígenas, y la Convención Internacional sobre todas las Formas de Discriminación Racial. Pero sobre todo, por la práctica de la CIDH y la jurisprudencia de la Corte Interamericana de Derechos Humanos, realizando una interpretación progresiva en sus sentencias.

(57) Ya en 2017, la Tribu Yaqui no solo luchaba por el reconocimiento de sus derechos ancestrales sobre el agua, el territorio y sus otros recursos naturales o su autonomía, sino sobre todo, por su sobrevivencia en un medio hostil. Y han tenido durante los pasados años un sonado éxito en la difusión de su lucha a través de diversos medios de información, convencionales y alternativos desde 2010, lo que a la fecha los visibiliza nacional e internacionalmente Así, se han hecho entrevistas y reportajes sobre su lucha para cadenas internacionales como la BBC (Nájar, Alberto, Yaquis, Los combatientes de la primera guerra del Agua en México, 31 de agosto de 2015, en: http://www.bbc.com/mundo/noticias/2015/08/150828_yaquis_mexico guerra_aguaan); o la cadena Russia Today: RT Noticias: Una Tribu mexicana defiende su territorio ancestral de un megaproyecto, 15 de noviembre de 2016, en: https:// actualidad.rt.com/actualidad/223691-tribu-yaqui-mexico-defender-territorio-gasoducto). La lucha yaqui también ha cautivado la atención de cineastas y documentalistas, ya que se han rodado películas y documentales sobre su cultura y lucha pacífica: Los Yaquis contra la serpiente de agua, o Mover un río, Laberinto Yoeme), por no hablar del sonado éxito mediático y el reconocimiento social amplio. 
La lucha yaqui ha costado también persecución penal y cárcel contra sus líderes y miembros de sus Autoridades Tradicionales ${ }^{(\mathbf{5 8})}$ entre 2011 y 2015. A las reivindicaciones yaquis los gobiernos han opuesto, con mala fe, los conceptos de "seguridad nacional", "proyecto estratégico" y recientemente, también "el Derecho humano al agua", refiriéndose al de la población de la capital del Estado, Hermosillo. (59) (60)

Pero los hechos son que, con base en los diferentes Tratados e instrumentos internacionales suscritos por el Estado Mexicano, la tribu Yaqui es sujeto de una protección especial que implica Derechos Colectivos que deben ser reconocidos, observados y respetados por todas las instituciones del Estado mexicano que a su vez debe imponerlos a los privados y a las compañías autóctonas o multinacionales de naturaleza extractiva. Estos derechos colectivos de los yaquis son plenamente exigibles al Estado Mexicano en todos sus niveles, según el marco jurídico internacional vigente.

Debe reconocerse también que la lucha yaqui ha tenido un éxito relativo. Destaca, como se ha explicado, la sentencia de Amparo en Revisión 631/2012 ${ }^{(61)}$ donde la Suprema Corte de Justicia de la Nación (SCJN) se ha pronunciado, así haya

(58) “Todos y cada uno de los pueblos tienen una jurisdicción definida y en su jurisdicción mantienen autonomía administrativa y cultural. Dentro de cada jurisdicción existen varias localidades y rancherías, coordinados mediante una organización de autodefensa y autogestión encabezada por su Autoridad Tradicional. La Autoridad Tradicional se conforma de una estructura civil y militar representados por los Gobernadores; Pueblo Mayor, Capitán, Comandante y Secretario; mismos que en el caso de los Gobernadores son elegidos por un periodo de un año pudiendo extenderse en casos muy especiales, hasta por dos periodos; el Pueblo Mayor, Capitán, Comandante y el Secretario regularmente son vitalicios, es decir, mientras no cometan un error grave el pueblo y la tropa los mantienen en sus cargos." Comunicado de la Tribu Yaqui, ante la Inauguración del Acueducto Independencia, 1 de diciembre de 2012.

(59) "En nuestra opinión, con estas disposiciones se conforma un estado con facultades discrecionales para decidir los usos futuros del agua, en beneficio de los consumidores de las ciudades pero en perjuicio de la población y actividades rurales, incluidas las comunidades indígenas. Además, es de preverse que la construcción de este tipo de obras hidráulicas generará impactos negativos en el ambiente y en las cuencas hidrológicas..." Moreno, 2014b.

(60) En febrero de 2012, la Comisión Nacional del Agua (Conagua) definió el proyecto del acueducto como "estratégico", argumentando que el suministro de agua a la ciudad de Hermosillo es un asunto de "seguridad nacional", agregando que la garantía del agua para uso personal y doméstico estaba prevista en la Constitución. Así, tal pareciera con el ejemplo citado, que cualquier argumentación vale para justificar la legalidad y pertinencia de los proyectos hidráulicos que decidan realizar los gobiernos estatales o el federal en todo el país, lo que parece tender a institucionalizar el desvío de recursos hídricos y su trasvase sin reparar en el despojo a pueblos y comunidades, con la consiguiente violación por parte del propio estado mexicano del Derecho Fundamental al Medio Ambiente sano y al agua en contra los sectores más desprotegidos de la población, señaladamente los pueblos indígenas. Ello sin perjuicio de las múltiples violaciones al Derecho de los pueblos indígenas a la libre determinación, a la Consulta Previa, libre e informada sobre cualquier proyecto de desarrollo realizado en sus territorios tradicionales.

(61) https://www.sitios.scjn.gob.mx/codhap/sites/default/files/engrosepdf_sentenciarelevante/12006310.002-1712_0.pdf); 
sido inefectivamente hasta ahora, en favor de la consulta libre e informada a la tribu Yaqui y en contra de las obras de infraestructura hidráulica que no les fueron consultadas. Es por ello que la tribu enfrenta en 2018 tareas importantes que pasan por ganar reconocimiento y autonomía territorial efectiva traducida en libre determinación, así como espacios políticos propios dentro de las evidentes limitaciones del sistema político y de elecciones mexicano. Otras comunidades indígenas, como los Caracoles Zapatistas en los Altos de Chiapas o los comuneros Purépechas de Cherán-Keri en la meseta de Michoacán, lo saben bien.

La práctica intercultural yaqui enriquece y empodera pacíficamente a los pueblos indígenas mexicanos en el reclamo de sus Derechos Fundamentales. Los Derechos Humanos, entonces, pueden redefinirse siguiendo a Joaquín Herrera Flores, como "el conjunto de procesos sociales, económicos, normativos, políticos y culturales que abren y consolidan desde el reconocimiento, la transferencia de poder y la mediación jurídica, espacios de lucha por la particular concepción de la dignidad humana" (HERRERA, Joaquín. s/f pág. 30).

\section{Bibliografía}

AAVV. 2016. México: Empresas y Derechos Humanos. Visita a México del Grupo de Trabajo sobre Empresas y DDHH. Compendio de información que presentan la Coalición de Organizaciones de la Sociedad Civil al Grupo de Trabajo sobre Empresas y Derechos Humanos de la ONU. 29 de agosto. Recuperado en: http:// www.prodesc.org.mx/index.php/es/2014-04-21-22-18-02/relacionados/592mexico-empresas-y-derechos-humanos

ABOITES, Luis y MORENO J.L. (2015). "Despojo de agua en la cuenca del río Yaqui", Hermosillo, Historia Mexicana, El Colegio de Sonora, Julio-Septiembre.

AGUILAR, Héctor (1985). La frontera nómada. Sonora y la Revolución Mexicana, CONAFE-SEP, México.

ALFIE, Miriam. (2015). “Conflictos socioambientales: la minería en Wirikuta y Cananena", El Cotidiano, número 191, may-jun 2015, Universidad Autónoma Metropolitana, Unidad Atzcapotzalco, D.F. México. En http://www.redalyc.org/ pdf/325/32538023011.pdf

BARRY, Tom (2015). Water Wars: water crisis destabilizing northern Mexico as the Yaqui lose major water battle in Sonora, Center for Internacional Policy, august. En: http://www.ciponline.org/images/uploads/publications/Water_Wars_TB_UPDATED.pdf 
BENGOA, José (2000). La Emergencia Indígena, Fondo de Cultura Económica, Santiago de Chile.

BURGER, Julian. (2014). “La protección de los pueblos Indígenas en el sistema Internacional". En: BELTRAO, Felipe [et al.] (coords.). Derechos Humanos de los Grupos Vulnerables. Manual. Barcelona: Red de Derechos Humanos y Educación Superior, 2014. Recuperado en: https://e-archivo.uc3m.es/handle/10016/19792

CALERO, Sofia. (2015). Windpower and environmental conflicts in the global south, Evidence from the isthmus of Tehuantepec, México; Barcelona, en: https://www. academia.edu/21564467/Wind Power and

CONSEJO NACIONAL DE EVALUACIÓN DE LA POLÍTICA SOCIAL (CONEVAL). 2012. La Pobreza en la población Indígena de México 2012. Recuperado en: https://www. coneval.org.mx/Informes/Coordinacion/INFORMES Y PUBLICACIONES PDF/POBREZA POBLACION INDIGENA 2012.pdf

GILLY, Adolfo (2015). "Sonora: La Nueva Guerra contra los Yaquis", La Jornada, 25 de febrero.

HARVEY, David, (2005). El nuevo imperialismo: acumulación por desposesión; Pantich, Leo y Colin Leys (ed.) El Nuevo desafío Imperial: 99-129. Buenos Aires: Merlin Press-Clacso.

HERRERA, Joaquín, s/f. Los Derechos Humanos en el contexto de la globalización, tres precisiones conceptuales, en: http://www.ces.uc.pt/direitoXXI/comunic/ HerreraFlores.pdf

HU, Evelyn (2016). The struggle for land Autonomy 1821-1910. Revised Edition. University of Wisconsin press.

INSTITUTO NACIONAL DE ANTROPOLOGÍA E HISTORIA, INAH, (2015), “La Tribu Yaqui y la defensa de sus Derechos territoriales", Diario de Campo, Tercera Época, Número 8, mayo-junio, Instituto Nacional de Antropología e Historia, México.

INSTITUTO NACIONAL DE ANTROPOLOGÍA E HISTORIA, INAH, (2015), "Peritaje Antropológico, impacto social y cultural por la operación del Acueducto Independencia", Rutas de Campo, Número 8, mayo-junio, Instituto Nacional de Antropología e Historia, México.

INSTITUTO NACIONAL DE ESTADÍSTICA Y GEOGRAFÍA, INEGI, (2018). En: www. cuentame.inegi.org.mx). 
JARAB, Jan. (2018). Los Derechos de los Pueblos Indígenas en México, una mirada desde el Sistema de Naciones Unidas. Oficina en México del Alto Comisionado de Naciones Unidas para los Derechos Humanos. México, Primera edición.

JIMENEZ, Alfredo. (2006). "Los Vecinos españoles ante los indios de Frontera: el Gran Norte de Nueva España", Brocar, Cuadernos de Investigación Histórica, No.30. Recuperado en https://dialnet.unirioja.es/servlet/articulo?codigo=2878408

LERMA, Enriqueta. (2014). "Notas para el análisis de la resistencia yaqui en contra del Acueducto Independencia", Sociológica, Vol.29, no.82. 255-271 en: http://www. scielo.org.mx/pdf/soc/v29n82/v29n82a8.pdf. Consultado el 25 de mayo de 2016.

LÓPEZ, Francisco. (2015).jLa tierra no se vende!, Las tierras y los territorios de los pueblos indígenas de México, Centro de Orientación y Asesoría a Pueblos indígenas, Tosepan, Instituto Mexicano de Desarrollo Comunitario, y Centro de Estudios para el Cambio en el Campo Mexicano, México.

LOPEZ, Francisco. S/f. En: http://www.lopezbarcenas.org/escrito/pueblos-indigenas-y-megaproyectos-en-mexico-las-nuevas-rutas-del-despojo);

LOPEZ, Francisco. S/f. Los Movimientos Indígenas en México, Rostros y Caminos, en: www.lopezbarcenas.org/escrito/los-movimientos-indigenas-en-mexico-rostros-ycaminos-1).

LUQUE Diana, tal. (2012) "Pueblos indígenas de Sonora, el agua ¿es de todos?". Región y Sociedad, en: ww.scielo.org.mx/scielo.php?pid=\$1870-39252012000600 003\&script=sci_arttext.

MACÍAS, Samantha, (2016). "En México, el mayor número de conflictos mineros de AL: 80 socio-ambientales y 22 laborales", Sinembargo: http://www.sinembargo. $\mathrm{mx} / 22-08-2016 / 3082109$

MANRÍQUEZ Y CASTRO. (2007). "Globalización y diversidad cultural en el Sonora contemporáneo. Variaciones sobre región, etnia y lenguaje", Región y Sociedad, Vol. 19, Hermosillo, Sonora, enero. Recuperado en: www.scielo.org.mx/pdf/regsoc/ v19nspe/v19nspea11.pdf

MARTíNEZ, José J. (2004). La gran migración blanca y la devastación de la población nativa a partir del siglo XV. Migración y Poblamiento en el noroeste de México. Memoria del XVII simposio de historia. Comp. por Arrizón, Faviola. 30-45. Hermosillo. Sociedad Sonorense de Historia. 
MARTíNEZ, J. (2015). “Ecología política del extractivismo y justicia socio- ambiental". Interdisciplina, Vol. 3, No.7, UNAM. http://www.revistas.unam.mx/index.php/ inter/article/view/52384

MORENO, José Luis. (2014a). Despojo del Agua en La cuenca del Rio Yaqui, El Colegio de Sonora, México.

MORENO, José Luis (2014b). "Trasvase de agua y conflicto ambiental en la cuenca del rio Yaqui", en: Tercer Congreso Red de Investigadores Sociales sobre Agua, 1114 de abril, 20114, México.

NÁJAR, Alberto, (2015). “Yaquis, Los combatientes de la primera guerra del Agua en México", 31 de agosto, en: http://www.bbc.com/mundo/noticias/2015/08/150828 yaquis mexico guerra aguaan);

ORGANIZACIÓN DE ESTADOS AMERICANOS (OEA). Corte Interamericana CIDH. $\mathrm{S} / \mathrm{f}$. Pueblos Indígenas y Tribales. Cuadernillo de Jurisprudencia de la Corte Interamericana de Derechos Humanos. Número 11. Recuperado en: http://www. corteidh.or.cr/sitios/libros/todos/docs/indigenas.pdf

ORGANIZACIÓN DE LAS NACIONES UNIDAS (ONU). Declaración de la ONU sobre los Derechos de Los Pueblos indígenas. Asamblea General, 13 de septiembre de 2007. En http://www.un.org/esa/socdev/unpfii/documents/DRIPS es.pdf

PADILLA, Raquel. (2015). “Peritaje Antropológico, Impacto social y cultural por la operación del acueducto independencia". Instituto Nacional de Antropología e Historia, INAH.

PASILLAS, Enrique. (2018). "Multiculturalismo y derechos fundamentales en el noroeste de México: El caso de la tribu yaqui", Estudios Fronterizos, Vol.19. Recuperada en: http://ref.uabc.mx/ojs/index.php/ref/article/view/658

PEREZ, Andrés. (1645) (Ed.1992). Historia de los triunfos de nuestra santa fe entre las gentes más bárbaras y fieras del nuevo orbe: conseguidos por los soldados de la milicia de la Compañía de Jesús en las misiones de la Nueva España. , Siglo XXI, México.

RESTOR, Macrina. (2015). "Plática sobre las comunidades Yaqui”, febrero, en: www. colson.mx

SPICER, Edward. (1994). Los Yaquis. Historia de una Cultura, UNAM, México.

STAVENHAGEN, Rodolfo, (1992). "Los Derechos Indígenas, algunos problemas conceptuales", en: Nueva Antropología, Vol. XIII, México. 
SUPREMA CORTE DE JUSTICIA DE LA NACIÓN, SCJN (2016). Acueducto Independencia Yaquis, Aclaración de Sentencia 631/2012, Amparo en Revisión 631/2012, http://www.sitios.scjn.gob.mx/codhap/completo/acueducto, Consultado el 30 de junio de 2016. México.

SVAMPA, Maristella. (2013). "Extractivismo en América Latina y el consenso de las commodities", 2013. El Correo de la Diáspora Latinoamericana. Recuperado en: http://www.elcorreo.eu.org/Extractivismo-en-America-Latina-y-el-Consenso-de-los-Commodities?lang=fr

TAIBO, Paco I. (2014). Yaquis: historia de una guerra popular y un genocidio en México, Grijalbo, México.

TOLEDO, Víctor (2016). “Hay en México 420 conflictos socioambientales: investigador", La Jornada, 11 de febrero.

TOLEDO, Víctor (2016). "Las Luchas Territoriales anuncian un cambio civilizatorio", La Jornada, 11 de octubre.

TOLEDO, Víctor (2016). “México, La rebelión silenciosa ya comenzó", La Jornada, 13 de septiembre.

TOLEDO Víctor y ORTIZ, Benjamín. (2014). México, regiones que caminan hacia la sustentabilidad, Una geopolítica de las resistencias bioculturales, Universidad Iberoamericana, Puebla.

TURNER, John K. (1910). Barbarous Mexico, Charles Kerr and Company Co-operative, Chicago. Recuperado en: 132.248.9.34/iih/001234242/001234242.pdf

ZÁRATE, José .L. (2016). “Grupos Étnicos de Sonora: Territorios y condiciones actuales de vida y rezago", Región y Sociedad, No 65, Hermosillo, Sonora. 